\title{
NOTAS SOBRE CONTRADIÇÕES E CRÍTICAS À PSICOLOGIA SOCIAL DE T. W. ADORNO
}

\author{
NOTAS SOBRE CONTRADICCIONES Y CRÍTICAS DE LA \\ PSICOLOGÍA SOCIAL DE T. W. ADORNO
NOTES ABOUT CONTRADICTIONS AND CRITICISMS OF T. W. ADORNO'S SOCIAL PSYCHOLOGY

\author{
José Leon Crochick ${ }^{1}$, Herik Rafael de Oliveira², \\ Francis Armando dos Santos Fuchs ${ }^{1}$ e Sandy Lira Ximenes Lima ${ }^{1}$ \\ ${ }^{1}$ Universidade Federal de São Paulo, São Paulo/SP, Brasil \\ ${ }^{2}$ Universidade de São Paulo (USP), São Paulo/SP, Brasil
}

RESUMO: Este artigo busca indicar o que se supõe configurar três contradições lógicas no ensaio "Sobre a relação entre sociologia e psicologia" e no "Pós-escrito" - escritos de Theodor Adorno. Essas contradições, não dialéticas, referem-se: à aceitação do conceito de "psicologia social", às implicações da psicoterapia e à divisão do trabalho acadêmico entre sociologia e psicologia. Para tanto, analisaram-se argumentos que revelam a necessidade de uma "psicologia social analiticamente orientada" diante da relação antagônica entre indivíduo e sociedade; refletiu-se acerca dos limites da psicologia do indivíduo considerado como uma mônada; e, por fim, perguntou-se pela distinção do objeto de estudo no âmbito da sociologia e da psicologia e pela objetividade da separação entre sociedade e indivíduo no capitalismo tardio determinante das contradições entre essas ciências.

PALAVRAS-CHAVE: Teoria Crítica da Sociedade; Psicologia Social Analiticamente Orientada; Dialética.

RESUMEN: Este artículo busca indicar lo que se supone configura tres contradicciones lógicas en el ensayo "Sobre la relación entre sociología y psicología” y en "Posdata" - escritos de Theodor Adorno. Estas contradicciones no dialécticas se refieren a: la aceptación del concepto de "psicología social”, las implicaciones de la psicoterapia y la división del trabajo académico entre sociología y psicología. Para tanto, se analizaron argumentos que revelan la necesidad de una "psicología social de orientación analítica" ante la relación antagónica entre individuo y sociedad; se llevó a cabo reflexión sobre los límites de la psicología del individuo considerado como mónada; y, finalmente, se preguntó sobre la distinción del objeto de estudio en el ámbito de la sociología y la psicología y la objetividad de la separación entre sociedad e individuo en el capitalismo tardío que determina las contradicciones entre estas ciencias.

PALABRAS CLAVE: Teoría Crítica de la Sociedad; Psicología Social de Orientación Analítica; Dialéctica.

ABSTRACT: This article aims to investigate three possible logical contradictions in the essay "Sociology and Psychology" and in its "Postscript" - writings by Theodor Adorno. These contradictions, not dialectical, refer to the acceptance of the concept of "social psychology" by the author, to the implications of psychotherapy and to the division of academic work between sociology and psychology. Therefore, arguments that reveal the need for an "analytically oriented social psychology" in the face of the antagonistic relationship between individual and society were analyzed; the limits of the psychology of the individual as a monad were discussed; and, finally, we questioned the distinction between sociology's and psychology's object of study, as well as the objectivity of the separation between society and individual in the late capitalism that determinates the contradictions between these sciences.

KEYWORDS: Critical Theory; Analytically Oriented Social Psychology; Dialectic. 


\section{Introdução}

O presente artigo fundamenta-se em reflexões acerca do ensaio "Sobre a relação entre sociologia e psicologia", elaborado por Theodor W. Adorno (1955/2015b), e do "Pósescrito" adicionado pelo autor ao texto original onze anos depois. Neste último, Adorno (1966/2015c) apresenta, em oito teses, reformulações consideradas necessárias por ele, tendo em vista sua insatisfação com alguns aspectos contidos na primeira publicação. $\mathrm{O}$ acréscimo foi feito a partir do confronto com reflexões propiciadas por um simpósio ocorrido em 1965 na Sociedade Alemã de Sociologia, cuja temática tratava da relação entre sociologia e psicologia.

A partir da leitura e análise do ensaio e do pós-escrito, este trabalho tem como objetivo indagar se há, nesses textos, três contradições, consideradas como lógicas, e não como contradições do objeto, observadas no pensamento do autor frankfurtiano. Tratar de possíveis contradições lógicas não significa perscrutar o texto à caça de eventuais sofismas nele contidos que possam ser tomados como elemento de acusação contra a teoria de Adorno, mas de apontar limites de seu pensamento talvez não percebidos por ele e, assim, não superados. O impulso orientador do exercício proposto provém dos modelos de pensamento que fundamentam uma "dialética aberta", assim referida por Adorno (2013, p. 65) em uma de suas vinte lições ministradas no ano de 1958, reunidas sob o título "Introducción a la dialéctica", na edição argentina.

O autor descreve como ineludíveis as dificuldades encontradas no movimento de reflexão ao relacionar os momentos de objetos específicos com a totalidade. Elas não são equiparáveis aos equívocos do pensamento, às contradições lógicas, como advogam as leis da lógica estrita que as perseguem e tentam suprimir aquelas dificuldades, que são provenientes das contradições objetivas, diferindo-se, assim, dos erros pelos quais o sujeito cognoscente é o responsável. Tais contradições objetivas são o material da dialética, que não deixa de reconhecer a própria lógica formal, sem eximi-la da crítica necessária. $\mathrm{O}$ autor enfatiza que a dialética não é ilógica: a lógica formal é um dos seus momentos; sua consideração é tanto mais importante quanto mais desata o pensamento do emaranhado inicial de suas confusões.

Coincidem em sentido os esforços presentes nos ensaios de Adorno, aqui analisados, e neste estudo a respeito da premência de uma crítica à ciência psicológica, ciência essa que arrefece e concilia diante de seus impasses mais consequentes. Por isso, deve-se indicar, nesses textos, pontos que se mostram logicamente contraditórios, quando o autor aparenta aceitar propostas vinculadas ao que foi veementemente criticado por ele mesmo.

Considerando também o lugar ocupado pela psicologia social na obra de Adorno, ressalta-se a necessidade de delimitação da compreensão encontrada no pensamento do autor a respeito dessa disciplina (Crochík, 2008, 2018; Crochík, Dias, \& Silva, 2015). O presente estudo também se inscreve na busca por essa delimitação na medida em que visa a desdobrar elementos das reflexões e contradições lógicas de Adorno.

A primeira contradição lógica observada refere-se a decorrências da aceitação por parte de Adorno do conceito de "psicologia social", sem considerar, como Freud (1921/2011) o fez, a redundância da expressão. Esse conceito encontra limites ante a primazia da sociologia em relação à psicologia, conforme o autor discute. A demarcação 
de uma psicologia social, distinta de uma psicologia não adjetivada, pode implicar, nesta última, a restrição da crítica quanto àquelas proposições que prescindem de seu objeto como socialmente determinado.

A segunda contradição lógica diz respeito ao estatuto da psicoterapia. A crítica de Adorno não faz concessões nem mesmo às práticas clínicas psicanalíticas - conquanto a teoria sexual de Freud seja reivindicada em seu potencial esclarecedor - e sua natureza regressiva e, não intencionalmente, fraudulenta, que é evidenciada. De modo paradoxal, a psicoterapia psicanalítica é pontualmente indicada pelo autor em alguns casos típicos, casos nos quais vestígios da autonomia do psicológico ante a racionalidade social pode ser notada. Os traços, nos quais desponta algo de autonomia, assinalam que a possibilidade de realização da diferenciação individual está contida no todo contraditório, ainda quando prevaleça a condição de heteronomia.

A terceira contradição lógica está relacionada à divisão de trabalho entre sociologia e psicologia que é, em alguns trechos dos textos, legitimada por Adorno. Tal divisão é determinada pela separação objetiva, simultaneamente, verdadeira e falsa, entre sociedade e indivíduo conforme o autor indica. Portanto, aquela divisão também é dialética. A aquiescência no âmbito do conhecimento com essa divisão acaba por insistir no que a cisão tem de mentira, ou seja, que a sociedade nada tem a ver com o indivíduo e vice-versa. $\mathrm{O}$ proceder oposto, o de afirmar uma afinidade irrestrita entre a sociologia e a psicologia, ignora a verdade de que a sociedade se apartou da realização do indivíduo.

Como procedimento, procura-se manter o foco no ensaio e no pós-escrito e são sublinhados excertos nos quais podem ser observadas essas três contradições lógicas, ainda que, por vezes, sejam utilizados outros de seus textos. Os trechos aparecem neste artigo como citações confrontadas com as próprias reflexões de Adorno. Portanto, não se trata de uma crítica movimentada desde referenciais extrínsecos, e sim, nos textos aqui analisados. Se há essas contradições lógicas, ao indicá-las, o pensamento torna-se capaz de sua superação e isso o libera em seu movimento de se aproximar das contradições objetivas, permitindo o avanço da crítica, e, neste caso, a crítica à ciência psicológica, potencializando sua relevância na análise da dominação social.

Antes de iniciar a análise, cabe ressaltar que as categorias psicológicas e psicanalíticas, no modelo freudiano, constituem um dos eixos importantes para as proposições analíticas e conceituais da Teoria Crítica da Sociedade, principalmente nos textos de Horkheimer e Adorno. Em seus escritos, os autores não operam simplesmente com conceitos psicológicos para constituição de um diagnóstico acerca da sociedade, mas apontam os limites, insuficiências e contradições nesses conceitos e na relação entre a psicologia e a sociologia. Adorno (1955/2015b,1966/2015c) remete essas contradições, insuficiências e limites à própria materialidade. Elas são engendradas pela separação real entre sociedade e indivíduo, e, por isso, podem tanto refletir essa separação no sentido de espelhar e, portanto, mantê-la intocada, como no sentido de proporcionar reflexão sobre a mesma.

Crochík (2008), indicando que o indivíduo é formado socialmente, afirma que é impossível compreendê-lo apenas pela perspectiva psíquica; a dominação, contudo, alcança o interno, que é, por outro lado, ponto-cego da sociologia tal como se configurou historicamente. Nesse sentido se dá a crítica de Adorno ao demarcar a necessidade de uma "psicologia social analiticamente orientada" para compreender a regressão psíquica dos indivíduos contemporâneos fundada pela repressão social (Adorno, 1955/2015b). 


\section{A necessidade de uma psicologia social analiticamente orientada}

Adorno (1955/2015b) inicia seu ensaio indicando que a tendência observada da massa aderir ao sacrifício e ao perigo do fascismo não se deixava compreender pelo desgastado argumento do controle sobre a opinião pública. O entendimento dessa entrega à tendência destrutiva implicou, então, analisar como as dinâmicas internas correspondiam ao que é solicitado objetivamente. A importância de iluminar essa problemática por meio do conhecimento em psicologia, completando a Teoria da Sociedade com a "psicologia social analiticamente orientada”, se impôs. Tal proposição, enunciada logo no início do escrito, é consequência das reflexões de Adorno acerca das relações entre sociologia e psicologia. Depois de pôr em tensão a separação entre ambas as ciências e seu fundamento - a cisão entre sociedade e indivíduo - a "psicologia social" seria (re)apresentada como resposta, configurando um modelo para compreensão do momento psicológico da dominação social inspirado, em especial, pela psicanálise, o que ocorre ao final do pós-escrito formulado por Adorno.

A ideia de "psicologia social", indicada ao final do pós-escrito, assim como a proposição nomeada de "psicologia social analiticamente orientada", verificada no início do texto de 1955, podem ser remetidas a trabalhos anteriores de Erich Fromm, como o tex to "Método e função de uma psicologia social analítica" (1932/1977), no qual o autor se dedica a discutir a aproximação entre psicanálise e marxismo. Assim, quanto à expressão "psicologia social analiticamente orientada”, cabe considerar o diálogo estabelecido com as formulações prévias de Fromm, ainda que tal expressão seja comumente assumida como nomenclatura proposta por Adorno.

A compreensão da "psicologia social analítica”, nos moldes projetados por Fromm, ilumina a psicologia social defendida por Adorno, considerando que esse discute a psicologia social em um sentido distinto e suas críticas, todavia não façam referência direta a Fromm, alcançam a psicologia social proposta por ele. Enquanto Fromm (1932/1977) inscreve a psicologia social nas ciências naturais, Adorno a compreende como ligada às ciências sociais, como uma disciplina sociológica (Crochík, 2008). A diferença aí observada não se resume no mero arranjo das disciplinas no quadro geral do conhecimento, mas implica importantes distinções na concepção do objeto.

No caso de Adorno (1955/2015), é aprofundado o entendimento do psicológico como produto da determinação social. Assim, não é incólume a expressão "psicologia social”, cuja redundância se nota ao demarcar a natureza social do psicológico, que é fundado pelas determinações sociais. O próprio Freud (1921/2011), em sua obra "Psicologia das massas e análise do eu", havia se dado conta de que toda psicologia é social. A partir disso, é possível questionar o assentimento de Adorno com relação a esse conceito, tal como encontra-se na primeira tese do "Pós-escrito":

o conceito de psicologia social não é tão equivocado quanto esta palavra composta e seu uso mundialmente disseminado fazem crer. A primazia da sociedade é reforçada retrospectivamente por aqueles processos psicológicos típicos, sem que aí se anuncie equilíbrio ou harmonia entre indivíduo e sociedade. (Adorno, 1966/2015c, p. 129) 
Se o conceito não é tão equivocado, como afirma Adorno, a justaposição que o forma, permanecendo irrefletida, corre o risco de perder aquela primazia da sociedade afirmada por ele como contraponto a uma insinuada simetria entre sociologia e psicologia. Enquanto vigora a sobredeterminação dos processos sociais e econômicos, a sociologia tem lugar privilegiado. Mas o psicológico e a sociedade não coincidem imediatamente, há entre eles diferenças qualitativas, historicamente necessárias: "Por mais que os indivíduos sejam produtos da totalidade social, tanto mais entram, enquanto tais produtos, em contradição com o todo" (Adorno, 1955/2015b, p. 80). Essas diferenças não podem ser facilmente abolidas e o progresso da dominação é índice disso; quanto mais avançam as condições materiais para a diferenciação, também se acirra a pressão social para impedi-la. Aquilo que o todo gera entra em conflito com o que o gerou, a própria sociedade nos estimula a ser diferençados e ela é contraditória quando obsta a individuação. A dominação é assegurada pelo controle no âmbito do sistema produtivo e lucrativo do mundo do trabalho e pelo domínio das necessidades e dos desejos por meio da repressão administrada pelas instituições e relações sociais.

O processo de especialização do trabalho, como no caso do trabalho artesanal, trouxe consigo uma exigência de diferenciação. A automação do trabalho, cujo resultado é a perda das diferentes qualidades das atividades, tem como decorrência que não é por vias do trabalho que a diferenciação será garantida. Com a automação, a liberdade do trabalho poderia significar abertura para que a diferença fosse possibilitada por outras esferas da cultura, o trabalho segue, porém, compulsório e desqualificado, e aquela potencialidade não se atualiza.

Nesse sentido, a organização social é contraditória, pois, ao mesmo tempo que permite produzir as condições para sua superação, converte-se em um sistema que tem a manutenção de si mesmo como fim, submetendo a humanidade. Adorno (1955/2015b) menciona a “interminável tradição do negativo" (p. 96) para dizer da reposição dos impedimentos à liberdade e à felicidade no curso da história. Na psicologia individual isso transparece. Segundo o autor "as diferenças específicas do indivíduo são tanto marcas da pressão social quanto cifras da liberdade humana” (p. 81), de modo que nelas se expressam o que seria possível e é reprimido. Assim, a constituição traumática do psiquismo, observada por Freud, revela o potencial presente na psicanálise quando ela denuncia a violência desmesurada - o "aumento excessivo de excitações", que é também o impedimento acumulado da satisfação pulsional -, diante da qual o indivíduo é debilitado. Laplanche e Pontalis (1967/1985) discutindo a respeito do trauma na obra de Freud indicam que:

o princípio de prazer, para poder funcionar, exige a realização de determinadas condições, condições que o traumatismo vem abolir, na medida em que não é uma simples perturbação da economia libidinal, antes vem mais radicalmente ameaçar a integridade do indivíduo... (p. 683)

Amparados nas reflexões de Adorno (1955/2015b), é possível indicar que o conhecimento voltado ao psicológico deve decifrar nele as marcas da dominação, pondose em defesa de desencantar o sempre igual traumático, rompendo a repetição impeditiva do novo. O desejo foi negado, a diferença foi brutalmente castrada, mas não pôde ser completamente anulada, deixou testemunhos de sua reivindicação: os sintomas, nos quais sobrevive - em estado de extremo sofrimento que é a condição do inadaptado no mundo - a recusa à completa funcionalidade. Se bem que se expressem no âmbito do psiquismo, 
esses processos apontam, primordialmente, para a formação e, portanto, para a dominação social, que não pode ser superada pelo tratamento das consequências subjetivas.

Em outro estudo, Adorno afirma que teoria psicanalítica freudiana resguarda a liberdade justamente porque seu próprio "conceito de psicologia é essencialmente negativo" (Adorno, 1951/2015a, pp. 186-187). Assim, é possível compreender que, com a expressão “analiticamente orientada”, Adorno (1955/2015b) caminha com a crítica esclarecedora do pensamento de Freud e seu potencial de negação e, ao mesmo tempo, diferencia do que é proposto pela prática psicanalítica de consultório, indicando seus limites. Tais limites não são, como é possível imaginar, ordem de uma demarcação exterior, e sim a insuficiência a que se conduzem os próprios argumentos e implicações da psicanálise. O mergulho segue até onde os conceitos apresentam a asfixia, que não é primeira neles mesmos - embora muitas vezes lhes seja atribuída a culpa pelo sufoco -, mas expressão da claustrofobia geral, social. Enquanto fornecem algum ar, perde-se de vista que se está no escuro, envolto dos pés à cabeça, sob forte pressão. Como cerne de uma contradição que será analisada mais detidamente, a prática psicanalítica incide justamente nisso, conforme é possível indicar com Adorno (1955/2015b) e sublinham Crochík, Dias e Silva (2015).

Há, também, a tendência não menos destrutiva de converter a asfixia em condição constitutiva irrevogável, acompanhando como expediente ideológico aquele papel da psicanálise como profissão socialmente útil. Isso se acirra com o ímpeto totalitário psicanalítico, cujas expressões podem ser encontradas tanto em intérpretes e continuadores do pensamento freudiano, quanto no próprio Freud (Adorno, 1955/2015b). Segundo Adorno é esse o caso, por exemplo, de Anna Freud. Ela elevou os mecanismos de defesa a ponto de nada lhes escapar, nem mesmo realizações culturais, que têm outras determinações mais importantes. Tornando hipóstase esses mecanismos psíquicos, considera natural a história, quando deveria levar ao questionamento de o quê na totalidade social requer essa defesa perene sedimentada na constituição individual. Seguindo as análises do frankfurtiano, um movimento semelhante apresentou-se em Freud na extrapolação feita por ele das imagens psíquicas para a interpretação da cultura e da sociedade - o pai da horda primitiva é um exemplo. Nesse ponto, Adorno indica que "Freud esquece as próprias modificações, descobertas por ele, de todo real no inconsciente, e, assim conclui equivocadamente por realidades factuais" (Adorno, 1955/2015b, p. 96).

Esse movimento de contrapor o pensamento de Freud às suas próprias consequências é característico da crítica como apontamento de limites de modo imanente, e não exterior. Sendo exterior, a crítica reduz-se ao momento da síntese: na qual, quando um conhecimento apresenta suas aporias, outro conhecimento desenvolve suas antíteses, outra disciplina é convocada a integrá-las e eliminá-las, mas não avança rumo ao esclarecimento. Esse não é o caso, pois a psicanálise é levada a tomar como objeto de reflexão seus próprios pensamentos. Adorno (2013) afirma que a dialética, "em um sentido eminente, é a filosofia kantiana levada a sua compreensão de si mesma, à sua autoconsciência” (p. 53). Talvez seja possível estender tal entendimento à posição da psicanálise na psicologia social adorniana, pensada dialeticamente. Nesse sentido, quando a psicanálise preza pelo impulso à autoconsciência realizado no contato e crítica de suas contradições, ela tem potencial esclarecedor. Cabe apontar, porém, que não se trata de simplesmente afirmar a dialética, pois ela não se consuma apenas ao informar que a concepção do indivíduo adotada é "em relação dialética com a sociedade”; aí está presente aquela exterioridade pura, resultado sem processo exposto em primeiro lugar. 


\section{A psicologia do indivíduo monadológico}

Para Adorno (1955/2015b), os determinantes sociais são predominantes sobre o desenvolvimento individual; não que conceitualmente os elementos psicológicos se reduzam aos sociais, mas no sentido de que na sociedade administrada há uma predominância do todo sobre a parte. Mesmo que a sociologia não tenha em seu escopo de maneira sistemática e analítica o estudo dos elementos idiossincráticos e individuais, a dinâmica, ou estática, entre eles depende do sistema social, assim, “o indivíduo não é simplesmente indivíduo e substrato da psicologia, mas sempre e ao mesmo tempo portador das determinações sociais que o marcam" (Adorno, 1955/2015b, p. 81). Desse modo, não é possível pensar cada época como geradora de suas próprias doenças psíquicas (síndromes, transtornos e neuroses), mas o indivíduo é levado às regressões conforme as necessidades sociais vigentes ao seu tempo.

Nesse sentido, Adorno (1955/2015b) critica a psicologia que sustenta que o indivíduo por suas próprias forças conseguiria superar as suas dificuldades nesta sociedade. Caberia à psicologia, no sentido de uma psicologia negativa, a crítica do que impede cada indivíduo de tornar-se individuado, ou seja, a psicologia como uma denúncia à sociedade que gera sofrimentos ao indivíduo por seguir alheia ao particular, perpetuando-se como um todo opressivo. O autor faz, por esse motivo, explícito o "psicologismo preponderante da or todoxia freudiana" (Adorno, 1955/2015b, p. 84). Ela e toda teoria que parte do pressuposto de que seu objeto é o indivíduo constituído, diferençado, independentemente da sociedade que o desenvolve, torna-se ideologia. Só é possível a diferenciação do indivíduo em uma sociedade sem a carência e a desigualdade material que, proporcionando o tempo livre, oferte meios para que a diferença seja expressa. A expressão implica, ainda, a riqueza cultural assegurada a cada um, por meio da qual os medos, receios, limites, frustrações e também os desejos e expectativas podem encontrar lugar no mundo sem serem reprimidos ou pobremente compensados. Se a cultura se mantém empobrecida, o indivíduo pouco poderá expressar e refletir, tendo em vista que não poderá diferenciar os objetos mais apropriados a seus desejos. A diferenciação consiste justamente na possibilidade de distinção entre os objetos que de fato poderão atender aquilo que se deseja, tendo assim um duplo movimento: de relação com os objetos para perceber até que ponto eles atendem ou não os desejos do indivíduo; e, ao mesmo tempo, o de conhecimento do desejo individual em buscar objetos que possam atender a este. A psicanálise fornece aportes para tal compreensão, e, a um só tempo, sua ambivalência também a fez argumentar contrariamente a isso.

A crítica à psicanálise também se volta ao fato de que Freud não percebeu que o eu é ao mesmo tempo um feixe de pulsões e um produto do meio, e, ao negar a oposição destas duas forças, a psicanálise nega o cerne da teoria analítica - "o conflito do eu e do isso" (Adorno, 1955/2015b, p. 85). As reações do meio são incorporadas para fazer negociação com os nossos desejos; então, o eu é, ao mesmo tempo, esse feixe de pulsões e adaptação ao mundo. $\mathrm{O}$ eu precisa modificar o mundo que recebe para realizar a pulsão e precisa transformar a pulsão para que ela possa ser realizada de forma não destrutiva. $\mathrm{Na}$ sociedade do capitalismo tardio, em que as relações entre sociedade e indivíduo se automatizaram em favor da própria sociedade, as tendências sociais são impostas a tal ponto que os indivíduos não são capazes de reconhecê-las, criando-se um "véu social" (Adorno, 1955/2015b, p. 86). Por isso, as pulsões não são elementos meramente psíquicos, mas também dependem da cultura para se movimentar satisfatoriamente em direção aos 
objetos que lhes sejam pertinentes; elementos da cultura que penetram e se preservam no indivíduo. Freud tende a ver o eu mais como uma tendência psíquica, e, sobretudo, de defesa, do que algo que necessariamente incorpore o mundo. Se a mediação entre indivíduo e sociedade se dá no eu, ele contém essa contradição: é eu e não-eu (Adorno, 1955/2015b).

Adorno (1955/2015b) afirma: "o conceito do eu é dialético, psíquico e não psíquico, um fragmento da libido e o representante do mundo" (p. 107). O autor marca que essa dialética do eu não estava clara para Freud e a carência dessa compreensão se exprimia justamente nas flagrantes contradições que despontavam na conceituação do eu, tanto mais o pensamento freudiano buscava firmar o sistema absolutamente interno e explicável intrinsecamente. Ao visar o eu apenas enquanto fragmento da libido reafirma-se o seu caráter de mônada; os impedimentos aos desejos impostos pela cultura são, por seu turno, ignorados. A incompreensão da psicanálise quanto à dialética do eu revela que, embora Freud tenha indicado a submissão dessa instância àqueles seus dois senhores, o supereu e o isso, ele não conseguiu avançar para a cultura que forma o eu por dar predominância ao psíquico. E essas asserções permitem novamente explicitar a primeira questão deste texto a respeito da distinção entre a psicanálise e uma psicologia social analiticamente orientada, pois, se o eu é dialético, no sentido discutido, toda psicologia, como defendeu Freud, não é também psicologia social?

A despeito dessa compreensão, encontra-se nas páginas finais do ensaio de 1955 o seguinte apontamento:

Quando alguém comete um ato falho e deixa escapar uma palavra com coloração sexual; quando alguém tem fobia de lugares ou uma mulher é sonâmbula, então a psicanálise possui não apenas suas melhores chances terapêuticas, como também seu objeto próprio: o indivíduo relativamente autônomo, monadológico, como palco do conflito inconsciente entre moção pulsional e proibição. (Adorno, $1955 / 2015$ b, p. 125)

Interessa indicar o contraste entre as afirmações desse excerto e outro trecho anterior no qual Adorno discute as relações entre a sociedade e as neuroses, tecendo críticas à psicoterapia, diz o autor:

Mesmo a cura bem-sucedida carrega o estigma do danificado, da vã adaptação pateticamente exagerada. O triunfo do eu é o triunfo da cegueira produzida pelo particular. Este é o fundamento da inverdade objetiva de toda psicoterapia, que incita os terapeutas à fraude. Na medida em que o curado se assemelha à totalidade insana, torna-se ele mesmo doente, mas sem que aquele que fracassa em ser curado seja por isso mais saudável. (Adorno, 1995/2015b, p. 90)

Aqui entram em confronto explícito as pungentes críticas do autor à psicoterapia, incluindo sua versão psicanalítica, a qual é reposição da dominação: (a) por seu papel adaptativo; (b) por advogar a favor da deposição das defesas quando elas são a formação do sintoma do indivíduo impotente ante a violência objetiva; (c) por responder à própria desigualdade social, tal como Adorno (1955/2015b) assevera quanto às diferentes modalidades terapêuticas oferecidas aos ricos neuróticos e aos pobres psicóticos; e, enfim, (d) por fazer alarde de seus sucessos clínicos quando eles são a própria derrota individual perante à totalidade que é apaziguada pelo alinhamento do que neste ainda era ruidoso. 
Ao ceder ao ímpeto de circunscrever um legítimo campo da psicoterapia, um quadro de atuação da psicanálise sobre problemas considerados psicológicos (os atos falhos, chistes, casos de fobia ou sonambulismo), a tensão e crítica à psicanálise se perdem, demarcando com a teoria um domínio no qual o próprio pensamento tem restrições para penetrar porque as "melhores chances" já estão garantidas à prática.

Outra contradição evidente pode ser explicitada sob a forma de questionamento: como é possível entender o indivíduo como mônada se a proibição - condição de heteronomia - é o que se confronta com a moção pulsional? Essa compreensão de indivíduo é aparência socialmente necessária. Enquanto ideologia, fundamenta práticas psicológicas pretensamente individualizantes, mas efetivamente voltadas para a atomização. A imposição de uma desmesurada suficiência da psicologia e da psicanálise na explicação das problemáticas também se nutre da ideia de indivíduo monadológico. Mesmo a percepção do indivíduo isolado é uma percepção social e se impõe justamente como impedimento para compreender as determinações sociais do irracionalismo vigente, o que é o mais decisivo, tal como é possível resgatar da reflexão inicial do ensaio de Adorno (1955/2015b).

A afirmação do entendimento do indivíduo como mônada ressurge na primeira tese do "Pós-escrito", contraditoriamente à enfática indiferenciação constatada:

A própria psicologia analítica conhece os motivos pelos quais um processo, embora tomem o indivíduo como seu palco e sejam nutridos pela energia pulsional individual, decorrem de forma tão uniformemente funesta. Segundo a forma, os processos individuais harmonizam-se extremamente com o movimento social universal. Em relação a isso, deve-se pensar tanto na constituição pré-individual e indiferenciada do inconsciente de cada um, tal como Freud descreveu, quanto no fato de que são bastante típicos os conflitos que o indivíduo experimenta nas fases decisivas de seu desenvolvimento, como os que ocorrem entre eles e as agências sociais, tal como a família. Isso foi demonstrado por Freud no modelo do Édipo. Não se deve hipostasiar, de fato, nenhuma consciência ou inconsciente coletivos; além disso, os conflitos se desenrolam, por assim dizer, sem janelas nos indivíduos e devem ser deduzidos nominalisticamente de sua economia pulsional individual - mas eles possuem forma idêntica em inumeráveis indivíduos. (Adorno, 1966/2015c, pp. 128-129)

As expressões da não diferenciação - "forma uniformemente funesta", "movimento social universal", "constituição ... indiferenciada", "bastante típicos os conflitos", "forma idêntica entre inumeráveis indivíduos" - contradizem a indicação de que os conflitos "se desenrolam sem janelas nos indivíduos" e devem ser compreendidos a partir da economia pulsional individual. A confrontação com o próprio movimento do autor pode ser retomada de sua discussão sobre a submissão do homo psychologicus ao homo oeconomicus, do "primado da economia sobre a psicologia no comportamento do indivíduo" (Adorno, 1955/ 2015 b, p. 79).

Esse primado se mantém não como invariante histórica e não por uma identidade imediata entre o comportamento e o interesse do lucro, e sim, coincide com o próprio alheamento da sociedade cuja reprodução alicia todos e cada um ao acionar o medo com base na coerção e vincular-se às necessidades psíquicas regredidas. Há, entre eles, mediações para que o insuportável e irracional possa ser vivido como inevitável e necessário. Disso resulta que falar da distinção, ou indistinção, entre psicológico e social sem falar da repressão é acentuar a repressão, como é o caso da ênfase no indivíduo e seus conflitos pulsionais. 


\section{A divisão do trabalho científico entre sociologia e psicologia}

Adorno (1955/2015b) insiste na impossibilidade de reconciliação conceitual da cisão entre sociedade e indivíduo condicionada materialmente, a cisão entre ambas não pode ser resolvida por vontade ou trabalho lógico do sujeito. Isso fundamenta a crítica às tentativas, com diferentes expressões, de sistematizar o trabalho científico para organizar as contradições objetivas. Sem perder os matizes consideráveis entre o que se chama de pluridisciplinaridade, multidisciplinaridade, interdisciplinaridade e transdisciplinaridade, persiste como denominador comum a ênfase disciplinar, porém, a centralidade deve ser da coisa a ser conhecida. Para Adorno (1966/2015c): "Mesmo a mais perfeita colaboração interdepartamental não eliminaria a divergência da própria coisa” (p. 129).

Esse aspecto subsidia os limites na proposição de uma psicologia social na qual transita-se facilmente entre psicologia e sociologia considerando ambas como igualmente importantes. Isso não significa que as rígidas fronteiras entre disciplinas devem ser conservadas porque assim se estabeleceram no processo de esquematização das ciências parcelares. O decreto que institui fronteiras intransponíveis entre sociologia e psicologia e a tentativa abrupta de fundi-las são, ambos, totalitários. Manter intocadas tais fronteiras é o mesmo que tornar natural esse processo e, nesse sentido, desponta outra contradição evidente nas formulações de Adorno (1966/2015c) quando afirma, a respeito da divisão entre sociologia e psicologia, que "Na medida em que a divisão do trabalho é conforme àquela real divergência, ela é legítima” (p. 129). O aspecto contraditório dessa proposição reside no fato de a atuação separada no âmbito da divisão do trabalho reproduzir cegamente a cisão da própria coisa. O sujeito do conhecimento resigna-se aos esquemas previamente estabelecidos.

A crítica de Adorno à teoria freudiana também pondera esses aspectos e permite discuti-los:

Freud, que não sem o ímpeto de expansão do especialista quis compreender enfim a sociologia como psicologia social aplicada, encontrou paradoxalmente o social (como a interdição do incesto, a internalização da imago paterna e formas das hordas primitivas) nas células psicológicas mais profundas. Quem separa sociologia e psicologia rigidamente uma da outra elimina interesses essenciais de ambas as disciplinas: o interesse da sociologia por sua relação retroativa aos seres humanos vivos, por mais mediada que esta seja; o da psicologia pelo movimento social de suas categorias monadológicas. (Adorno, 1966/2015c, p. 130)

Ao menos duas considerações podem ser desdobradas a partir do excerto. A primeira com relação à atribuição ao sujeito da responsabilidade pela separação entre sociologia e psicologia quando Adorno (1966/2015c) escreve "quem separa", contradizendo o contundente reposicionamento da fonte objetiva e não subjetiva dessa separação ${ }^{1}$. $O$ segundo aspecto não se configura como contradição lógica, e sim aponta para a superação dela. Adorno (1966/2015c) indica que no ímpeto especialista de Freud o objeto e sua complexidade irromperam para além de sua intenção. A imposição do objeto foi acolhida pelo pensamento freudiano, as aporias deram guarida às contradições objetivas. Isso ocupa no pensamento de Freud o lugar do paradoxal. 
Para Adorno (195 1/1993a), nos momentos de exagero da psicanálise está resguardada a verdade, ou seja, quando a psicanálise perde sua métrica própria, expressa a medida do objeto, embora sem a clareza disso. Isso aproxima Freud do que Adorno (2013) afirma sobre Kant a respeito de este não extrair as consequências de suas formulações. Em ambos, com formas e objetos distintos, talvez seja possível indicar um certo "esclarecimento não-esclarecido", que é atribuído a Freud nas formulações de Adorno (1951/1993b, p. 52). A obstinação freudiana no particular condensa o momento de esclarecimento e nãoesclarecimento e o pensamento precisa tomar consciência do que é não-esclarecimento para superá-lo. Embora os desvios do percurso programado, os rastros de passos titubeantes, tenham salvaguardado a verdade em movimento de perder-se, não cabe louvar o avanço cego em direção à parte nem ratificá-lo insistindo na continuidade da separação do trabalho científico. O não-esclarecido em Freud foi, de acordo com Adorno (1951/1993b), peça do jogo burguês, e, portanto, instrumento da dominação.

\section{Considerações finais}

Nos textos selecionados de Theodor W. Adorno, encontram-se três possíveis contradições lógicas aqui analisadas, que se contrapõem a um pensamento dialético, o qual, perante o exercício de reflexão, conduz às contradições imanentes ao objeto, mas, antes, deve superar a lógica da identidade entre conceito e objeto e não incorrer em contradições lógicas, com o risco de perder as próprias críticas estabelecidas.

A primeira contradição versa sobre o conceito "psicologia social", indicando que cada um de seus termos tomados de maneira semelhante a dois polos equivalentes em uma mesma equação ressoam como uma falsa conciliação e afinidade entre sociologia e psicologia. $\mathrm{O}$ avanço desse conceito, e de todos aqueles por ele mediados, queda impotente para a explicitação da repressão social enquanto sua radical contradição permanece suprimida ou atenuada: no mais interior das pessoas, da psicologia, encontra-se a sociedade; tal como depreende-se das reflexões de Adorno. Não parece ser essa a orientação fulcral de seu "uso mundialmente disseminado" em que se vê repetir conceitos como interação, influência ou papel para dizer da relação entre sociedade e psicologia individual.

Adorno assente que a psicanálise enquanto fazer social que precisa se legitimar pode beneficiar o indivíduo, contradizendo sua ferrenha crítica. Este é o âmago da segunda contradição lógica examinada. Adorno fundamenta essa afirmação com a concepção de um indivíduo isolado; concepção na qual transparece a ideologia desencoberta com veemência pelo próprio autor. Ademais, quando propõe contornos à prática psicanalítica, isso, que assume ares de uma autorização, deixa passar, por consequência, os aspectos tecnicistas e socialmente funcionais do conhecimento da psicanálise. O próprio pensamento se divide, estabelecendo como que critérios e ocupando-se do trabalho de apreciar em quais domínios cai melhor uma e outra coisa: a teoria ou a prática psicanalítica. Esse proceder sistematizador é o cerne da crítica que Adorno (1955/2015b) faz a T. Parsons e sua concepção de frames of reference.

Por fim, na última contradição lógica estudada, Adorno finda por concordar com a divisão do trabalho entre aqueles dedicados à sociologia e aqueles voltados à psicologia na medida em que o fundamento dessa separação é a divergência real entre sociedade e indivíduo. Esse argumento guarda o risco de justificar a submissão do conhecimento à 
lógica da divisão do trabalho e o decorrente enfraquecimento do pensamento que se dá sob sua fragmentação instaurada de maneira administrativa. É determinada por esse processo de sistematização a "decadência da dialética" observada por Adorno (2013), contra a qual sua obra é insurgente como objetivação de não conformidade com as fronteiras rígidas erigidas entre os conhecimentos a despeito de cada um dos objetos ser multívoco.

Desse modo, o presente estudo teve a intenção de apreender as contradições lógicas apresentadas prezando por não abrir mão da necessidade de superação. As dificuldades dessa tarefa, a grande exigência feita por ela ao pensamento, sinalizam sua distância daqueles posicionamentos que encontram alguma satisfação em estampar as incongruências dos pensadores, suas "insuficiências subjetivas", como nomeia Horkheimer no texto "Teoria tradicional e teoria crítica" (1937/1980, p. 128). O decisivo está em denunciar as insuficiências da vida condenada, que, por vezes, o pensamento insuficiente da lógica formal tenta encobrir ao se pôr como suficiente.

\section{Nota}

1. No cotejamento com a tradução do texto para o espanhol publicada pela Ediciones Akal no volume oito das obras completas de Adorno, "Escritos sociológicos I", não se encontra algo completamente paralelo com o "Quem separa ..." da versão em língua portuguesa traduzida por V. Freitas (Adorno, 1966/2015c, p. 130). Ao verter, o tradutor da versão madrilense consultada, A. G. Ruiz, opta por "Quien mantiene separadas ..." [grifo nosso] (Adorno, 1966/2004, p. 81). Há uma diferença não insignificante em dizer "quem separa" e "quem mantém separadas". No primeiro caso, a separação é realizada pelo sujeito; no segundo caso, a separação é mantida por ele. Nos dois casos permanece sobrestimado o papel desse sujeito: tanto a imposição quanto a manutenção da cisão entre sociologia e psicologia não podem ser explicadas, primariamente, pela vontade dos que a ela se dedicam ainda que essas determinações sociais materializem-se pelo atuar dos sujeitos. Assim, fica patente que a questão não diz respeito à tradução do texto, mas às formulações mesmas do autor. Todavia, cabe considerar que a tradução espanhola, ao não dizer que o sujeito cria a separação, e sim, que a mantém, apresenta maior precisão e aponta para a incorporação da ideologia que é própria a este sujeito. 


\section{Referências}

Adorno, T. W. (1993a). Frutas anãs. In Minima moralia: reflexões a partir da vida danificada (L. E. Bicca, trad., pp. 41-42). São Paulo: Ática. (Original publicado em 1951)

Adorno, T. W. (1993b). Aquém do princípio de prazer. In Minima moralia: reflexões a partir da vida danificada (L. E. Bicca, trad., pp. 51-52). São Paulo: Ática. (Original publicado em 1951) Adorno, T. W. (2004). Postscriptum. In Escritos sociológicos I (A. G. Ruiz, trad., Th. W. Adorno Obra Completa, Vol. 8, pp. 79-85). Madrid: Akal. (Original publicado em 1966)

Adorno, T. W. (2013). Introducción a la dialéctica (M. Dimópulus, trad.). Buenos Aires: Eterna Cadencia Editora.

Adorno, T. W. (2015a). Teoria freudiana e o padrão da propaganda fascista. In Ensaios sobre psicologia social e psicanálise (V. Freitas, trad., pp. 153-189). São Paulo: Editora Unesp. (Original publicado em 1951)

Adorno, T. W. (2015b). Sobre a relação entre sociologia e psicologia. In T. W. Adorno, Ensaios sobre psicologia social e psicanálise (V. Freitas, Trad., pp. 71-127). São Paulo: Editora Unesp. (Original publicado em 1955)

Adorno, T. W. (2015c). Pós-escrito. In T. W. Adorno, Ensaios sobre psicologia social e psicanálise (V. Freitas, trad., pp. 127-135). São Paulo: Editora Unesp. (Original publicado em 1966)

Crochík, J. L. (2008). T. W. Adorno e a psicologia social. Psicologia \& Sociedade, 20(2), 297305. Recuperado de http://www.scielo.br/pdf/psoc/v20n2/a17v20n2.pdf

Crochík, J. L. (2018). Teoria Crítica e psicologia social: relevância das pesquisas empíricas. Psicologia \& Sociedade, 30, 1-9. Recuperado de http://www.scielo.br/pdf/psoc/v30/18070310-psoc-30-e174315.pdf

Crochík, J. L., Dias, M. A. L., \& Silva, P. F. (2015). Crítica à psicanálise como fundamento da psicologia social de Adorno. Constelaciones: Revista de Teoría Crítica, 7, 322-342. Recuperado de http://constelaciones-rtc.net/article/view/1124/1150

Freud. S. (2011). Psicologia das massas e análise do eu. In Psicologia das massas e análise do eu e outros textos (1920-1923) (P. C. Souza, trad., Obras completas, Vol. 15, pp. 13-113). São Paulo: Companhia das Letras. (Original publicado em 1921)

Fromm, E. (1977). Método e função de uma psicologia social analítica. In A crise da psicanálise: ensaios sobre Freud, Marx e psicologia social (A. Cabral, trad., 2a ed., pp. 134-161). Rio de Janeiro: Zahar. (Original publicado em 1932)

Horkheimer, M. (1980). Teoria tradicional e teoria crítica. In V. Civita (Ed.), Textos escolhidos: Walter Benjamin, Max Horkheimer, Theodor W. Adorno, Jürgen Habermas (E. A. Malagodi \& R. P. Cunha, trads., Coleção Os pensadores, pp. 117-154). São Paulo: Abril Cultural. (Original publicado em 1937)

Laplanche, J. \& Pontalis, J. B. (1985). Trauma ou Traumatismo (psíquico). In Vocabulário da psicanálise (P. Tamen, trad., 8a ed., pp. 678-684). São Paulo: Martins Fontes. (Original publicado em 1967) 


\section{JOSÉ LEON CROCHICK}

https://orcid.org/0000-0002-2767-3091

Programa de Estudos de Pós-graduação em Saúde e Educação na Infância e na Adolescência da Unifesp.

Professor Titular aposentado do Instituto de Psicologia da USP; bolsista em Produtividade em Pesquisa do CNPq.

Endereço: Estrada do Caminho Velho, no 333 - Jd. Nova Cidade, Guarulhos /SP, CEP 07252-312.

E-mail: jlchna@usp.br

\section{HERIK RAFAEL DE OLIVEIRA}

https://orcid.org/OOOO-0001-5588-9132

Graduado em Psicologia pela Universidade Federal de São João del-Rei (UFSJ); mestrando no Programa de Psicologia Escolar e do Desenvolvimento Humano do Instituto de Psicologia da Universidade de São Paulo (USP).

E-mail: herikoliveira@usp.br

\section{FRANCIS ARMANDO DOS SANTOS FUCHS \\ https://orcid.org/OOOO-0002-3934-7621}

Licenciatura em Filosofia pelo Instituto Santo Tomás de Aquino (2011), bacharelado em Teologia pelo Instituto São Paulo de Estudos Superiores (2017) e mestrando em Educação pela Universidade Federal de São Paulo. Professor de Filosofia no Colégio Dom Bosco Mauá - Colleman.

E-mail: francis.armando@,hotmail.com

\section{SANDY LIRA XIMENES LIMA}

https://orcid.org/0000-0001-6728-0922

Graduada em Psicologia pela PUC-SP (2018), mestranda em Educação na UNIFESP. E-mail: sandyx3030@gmail.com 


\begin{tabular}{|l|l|}
\hline \multirow{3}{*}{ Histórico } & $\begin{array}{l}\text { Submissão: 06/03/2020 } \\
\text { Revisão: 09/05/2020 } \\
\text { Aceite: 11/05/2020 }\end{array}$ \\
\hline Contribuição dos autores & $\begin{array}{l}\text { Concepção: JLC; HRO; FASF; SLXL. } \\
\text { Coleta de dados: não se aplica } \\
\text { Análise de dados: não se aplica } \\
\text { Elaboração do manuscrito: JLC; HRO; FASF; SLXL. } \\
\text { Revisões críticas de conteúdo intelectual } \\
\text { importante: JLC; HRO; FASF; SLXL } \\
\text { Aprovação final do manuscrito: JLC; HRO; FASF; } \\
\text { SLXL. }\end{array}$ \\
\hline Consentimento de uso de imagem & Não se aplica \\
\hline Aprovação, ética e consentimento & Não se aplica \\
\hline Financiamento & $\begin{array}{l}\text { José Leon Crochick é bolsista em Produtividade em } \\
\text { Pesquisa do CNPq }\end{array}$ \\
\hline
\end{tabular}

